\title{
Improving Sports Technique of Key Elements in Dismounts on Uneven Bars Based Biomechanical Indicators
}

\author{
Vladimir Potop ${ }^{1, ~ a, ~ M a r i u s ~ S t a ̆ n e s c u ~}{ }^{2, \text { b }}$, Marian Crețu $^{3, c}$, \\ Olivia Carmen Timnea ${ }^{1, d}$
}

\author{
${ }^{1}$ Faculty of Physical Education and Sport, Ecological University of Bucharest, 061341, Romania \\ ${ }^{2}$ Central Military Hospital "Carol Davila", Orthopedics - Trauma Clinic“Gheorghe Niculescu”, \\ Bucharest, Romania \\ ${ }^{3}$ Deparment of Physical Education and Sport, University of Pitești, Romania \\ avladimir_potop@yahoo.com, bb01drj@yahoo.com, cmaryan_mc@yahoo.com, \\ doliviatimnea@zahoo.com
}

Keywords: Gymnastics, Uneven bars, Kinematics, Dynamics, Technical training, Performance

\begin{abstract}
Artistic gymnastics has made significant progress, proving that it develops in accordance with the trends of performance sport but it has its specific features too, such as: development of sports mastership, growth and rivalry of competitive programs, creation of new complex routines, sports mastery that reaches virtuosity; improvement of the components specific to the training of high classification gymnasts. The method of video-computerized analysis of double somersault dismounts off uneven bars, consistent with the method of movement postural orientation allowed to highlight and identify the biomechanical characteristics of the key elements whose assimilation deepens the understanding of sports technique and enables the development of modern programs for their learning.
\end{abstract}

\section{Introduction}

Gymnastics is one of the oldest Olympic sports. At the present moment, artistic gymnastics recorded remarkable progress, reaching a really high level of development so that gymnasts' performances differ by new elements, increased difficulty, complexity and spectacular character of exercises, concomitantly with improved technique and execution mastery [1,2].

Technical training includes the whole arsenal of methodic and organizational measures established during sports training with the purpose of acquiring the specific technique. It respects the physiological, biomechanical, aesthetic, psychological laws, relying on superior intellectual and emotional aptitudes of the gymnast [3].

In conformity with the requirements and the specific character of women's artistic gymnastics apparatus, the elements on uneven bars can be divided into several structural groups, defined not only according to their execution manner, but also according to their purpose, namely: handstands, hip circles (small and big), free passing over bars, somersaults and re-grasping, simple switches on longitudinal axis or made during different basic movements, transitions from one bar to another, mounts and dismounts [1, 4-7]; the dismounts off uneven bars correspond to the $6^{\text {th }}$ group of the International Code of Points, with the following difficulty groups and values [8]: group B -0.2 points - double back tuck somersault, group C -0.3 points - double back pike somersault and group D -0.4 points - double back tuck somersault with $360^{\circ}$ twist in the first somersault.

At the present moment, the scientific research has numerous concerns on the biomechanics issues in gymnastics. They are intended to help understand and classify based on the clear definition of movements study field. Current guidelines in the biomechanical research specific to this sports branch and the interest shown in this matter refer to the transfer of rotational movements, the mathematical modeling of the biomechanical indicators of back giant, the differences between the dismounts from front and back giant, the dismounts off uneven bars [3, 9-14]. Other issues that awaken researchers' interest worldwide are: similarities between the giant on high bar and the giant 
on uneven bars; elements with grasping and re-grasping of bar etc $[15,16]$.

The purpose of the paper is to highlight the dynamics of the kinematic and dynamic indicators of back double somersault dismounts off uneven bars of 12 to 15 years old gymnasts in training basic specialization stage.

Hypothesis of the paper. We consider that the biomechanical analysis of back double somersault dismounts off uneven bars based on the achievement of the macro methods of learning in the case of young gymnasts aged 12 to 15 will contribute to the development of sports technique key elements and to the improvement of dynamic and kinematic characteristics of the movement.

\section{Methodology}

The methodological character of this research consists of generalization and systematization of the large number of scientific data and the practical experience related to knowledge formation. Thus, the macro methods for learning the gymnastics exercises are presented as a modern dynamic system that includes and integrates the technological, didactical, biomechanical and motor structures of the exercises to be learnt. The objective practical-scientific argumentation for elaborating the macro methods to learn highly difficult gymnastic exercises was possible thanks to the use of modern theories [17].

This scientific approach entailed an experimental study made within the pedagogical experiment of the post doctoral thesis of the first author, selecting - from the final stage of the research - the dynamics of the biomechanical characteristics of dismounts off uneven bars. The research was conducted throughout the period 2012 - 2014, monitoring gymnasts' performances in three national competitions in uneven bars event. The subjects of the study were 7 athletes of 12 to 15 years old, members of junior national team of Romania.

Research methods used: method of theoretical and methodological analysis of literature related to artistic gymnastics; method of evaluation of gymnastics exercises sports technique by using the movement algorithmic analysis [7]; video computerized method, by means of: "Pinnacle Studio", "Kinovea" and "Physics ToolKit" programs; method of movement postural orientation and evaluation of key elements of sports technique with complex coordination of movement structure [18]; method of linear-branched programming of gy

mnastics exercises learning and improving [17]; statistical method by means of "KyPlot" program.

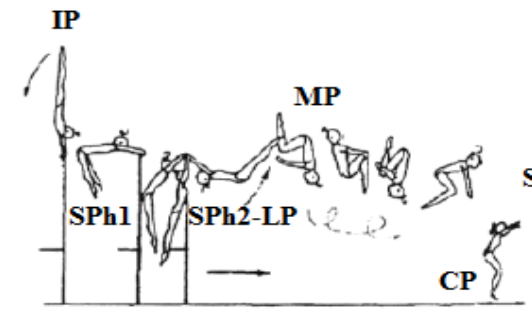

a) tucked

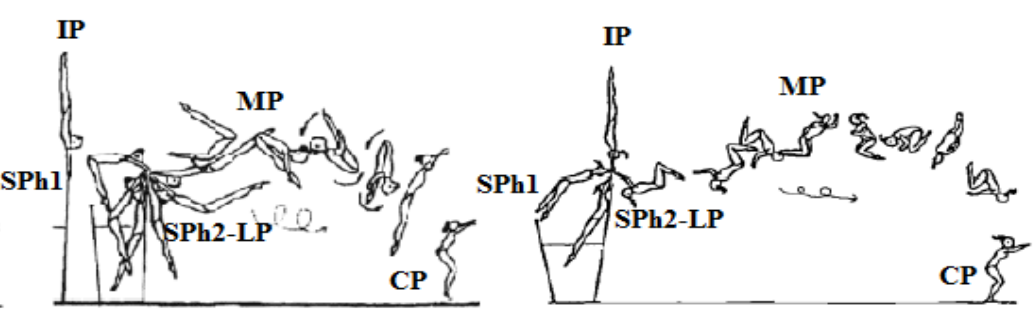

b) pike

c) tucked with $1 / 1$ turn $\left(360^{\circ}\right)$ in first salto Fig. 1 Key elements of sports technique used in double back somersault dismount off uneven bars.

The biomechanical analysis was made by means of Physics ToolKit Version 6.0 program. monitoring the key elements of sport technique of double back somersault dismounts, divided into two parts: rotation motion with rotation axis on apparatus, in terms of preparatory movement phase (PM): Sub-phase 1 (SPh1) spring under bar; Sub-phase 2 (SPh2-LP) body launching posture moment of release of the bar; translation and rotation motion with GCG rotation axis regarding the basic movement phase (BM) - multiplication of body position (MP) - somersault rotation and concluding movement phase $(\mathrm{CM})$ - concluding posture $(\mathrm{CP})$ of the body - landing. 


\section{Results}

Table no. 1 presents the results of calculation of arithmetical mean and standard deviation of anthropometrical and biomechanical indicators necessary for the biomechanical analysis of sports technique used in the dismounts off uneven bars in women's artistic gymnastics.

Table 1. Anthropometrical and biomechanical indicators necessary for the biomechanical analysis of sports technique used in the dismounts off uneven bars (mean \pm SD).

\begin{tabular}{|c|c|c|c|c|c|c|c|c|c|c|c|c|}
\hline \multirow{2}{*}{ Nr. Crt. } & \multirow{2}{*}{ Dismount } & \multirow{2}{*}{$\mathrm{N}$} & \multirow{2}{*}{$\begin{array}{l}\text { W. } \\
(\mathrm{kg})\end{array}$} & \multirow{2}{*}{ HwAU (m) } & \multirow{2}{*}{$\begin{array}{l}\text { I.R. } \\
\left(\mathrm{kg} \cdot \mathrm{m}^{2}\right)\end{array}$} & \multicolumn{3}{|c|}{$\mathrm{RM}^{1},(\mathrm{~m})$} & \multicolumn{4}{|c|}{$\mathrm{RM}^{2} / \mathrm{GCG},(\mathrm{m})$} \\
\hline & & & & & & Toes & GCG & Should & Toes & Knee & Shoulders & Arms \\
\hline 1 & TDS & 6 & \begin{tabular}{|l|}
1.90 \\
\pm 0.02 \\
\end{tabular} & $\begin{array}{l}34.65 \\
\pm 0.67 \\
\end{array}$ & $\begin{array}{l}125.56 \\
\pm 4.50\end{array}$ & \begin{tabular}{|l|}
1.75 \\
\pm 0.08 \\
\end{tabular} & \begin{tabular}{|l|l|}
1.05 \\
\pm 0.08 \\
\end{tabular} & \begin{tabular}{|l|}
0.56 \\
\pm 0.07 \\
\end{tabular} & \begin{tabular}{|l|}
0.56 \\
\pm 0.04 \\
\end{tabular} & \begin{tabular}{|l|}
0.32 \\
\pm 0.02 \\
\end{tabular} & \begin{tabular}{|l|}
0.42 \\
\pm 0.03 \\
\end{tabular} & \begin{tabular}{|l|}
0.40 \\
\pm 0.11 \\
\end{tabular} \\
\hline 2 & PDS & 33 & \begin{tabular}{|l|}
$1.87 \pm$ \\
0.07
\end{tabular} & $\begin{array}{l}34.98 \\
\pm 4.05 \\
\end{array}$ & $\begin{array}{l}123.76 \\
\pm 23.33\end{array}$ & \begin{tabular}{|l|}
1.66 \\
\pm 0.12 \\
\end{tabular} & \begin{tabular}{|l|}
0.98 \\
\pm 0.11 \\
\end{tabular} & \begin{tabular}{|l|}
0.53 \\
\pm 0.06 \\
\end{tabular} & \begin{tabular}{|l|}
0.71 \\
\pm 0.05 \\
\end{tabular} & - & \begin{tabular}{|l|}
0.38 \\
\pm 0.04 \\
\end{tabular} & \begin{tabular}{|l|}
0.40 \\
\pm 0.06 \\
\end{tabular} \\
\hline 3 & DSG360 & 12 & \begin{tabular}{|l|}
1.82 \\
\pm 0.04
\end{tabular} & $\begin{array}{l}33.49 \\
\pm 2.74\end{array}$ & $\begin{array}{l}108.74 \\
\pm 8.65\end{array}$ & \begin{tabular}{|l|}
1.57 \\
\pm 0.07
\end{tabular} & \begin{tabular}{|l|}
0.92 \\
\pm 0.06
\end{tabular} & \begin{tabular}{|l|}
0.51 \\
\pm 0.05
\end{tabular} & \begin{tabular}{|l|}
0.50 \\
\pm 0.06 \\
\end{tabular} & \begin{tabular}{|l|}
0.26 \\
\pm 0.03
\end{tabular} & \begin{tabular}{|l|}
0.34 \\
\pm 0.04
\end{tabular} & \begin{tabular}{|l|}
0.37 \\
\pm 0.04
\end{tabular} \\
\hline
\end{tabular}

Note: TDS - tuck double back salto; PDS-pike double back salto: TDS $360^{\circ}$ - tuck double back salto with $360^{\circ}$ twist (first salto); N - number of dismounts analyzed; W. - weight. H.- height. HwAU - height with arms up. I.R. - inertia of rotation. R.M. - radius of segments movement. Mean -arithmetical mean. SD - standard deviation. $\mathrm{RM}^{1}$ - phase of preparatory rotation motion on apparatus; $\mathrm{RM}^{2}-$ phase of flight basic motion.

Table 2. Indicators of angular characteristics of body segments during execution of sports technique key elements in dismounts off uneven bars.

\begin{tabular}{|c|c|c|c|c|c|c|c|c|c|c|c|c|}
\hline \multirow{3}{*}{ No. } & \multirow{3}{*}{ Dismounts } & \multirow{3}{*}{$\begin{array}{l}\text { Statistical } \\
\text { indicators }\end{array}$} & \multirow{2}{*}{\multicolumn{2}{|c|}{$\begin{array}{l}\text { SPh1 (deg) } \\
\text { thigh - torso }\end{array}$}} & \multicolumn{4}{|c|}{ SF2- LP (deg) } & \multirow{2}{*}{\multicolumn{2}{|c|}{$\begin{array}{l}\text { MP (deg) } \\
\text { thigh-torso }\end{array}$}} & \multirow{2}{*}{\multicolumn{2}{|c|}{$\frac{\mathrm{CP}(\mathrm{deg})}{\text { thigh-torso }}$}} \\
\hline & & & & & tors & $\mathrm{rms}$ & & rrso & & & & \\
\hline & & & $\mathrm{TI}$ & TF & TI & TF & TI & TF & TI & TF & $\mathrm{TI}$ & $\mathrm{TF}$ \\
\hline \multirow{5}{*}{1} & \multirow{5}{*}{$\begin{array}{l}\text { TDS } 360^{\circ}, \\
2012, n=3 \\
2014, n=3\end{array}$} & $\bar{x}$ & 142.3 & 137.3 & 129.7 & 123.3 & 144.3 & 153.3 & 104.7 & 99.3 & 100.7 & 127.7 \\
\hline & & $\mathrm{S}$ & 11.72 & 10.69 & 11.72 & 12.58 & 1.15 & 6.51 & 29.26 & 9.02 & 30.01 & 4.04 \\
\hline & & $\mathrm{Cv} \%$ & 8.23 & 7.78 & 9.04 & 10.20 & 0.80 & 4.24 & 27.96 & 9.08 & 29.81 & 31.66 \\
\hline & & $t_{i-f}$ & \multicolumn{2}{|c|}{0.546} & \multicolumn{2}{|c|}{0.638} & \multicolumn{2}{|c|}{$2.359 *$} & \multicolumn{2}{|c|}{$0.302 *$} & \multicolumn{2}{|c|}{$1.545^{*}$} \\
\hline & & $\mathrm{p}$ & \multicolumn{2}{|c|}{$>0.05$} & \multicolumn{2}{|c|}{$>0.05$} & \multicolumn{2}{|c|}{$>0.05$} & \multicolumn{2}{|c|}{$>0.05$} & \multicolumn{2}{|c|}{$>0.05$} \\
\hline \multirow{5}{*}{3} & \multirow{5}{*}{$\begin{array}{c}\text { PDS } \\
2012, \mathrm{n}=5 \\
2014, \mathrm{n}=9\end{array}$} & $\bar{x}$ & 148.0 & 182.1 & 117.8 & 132.2 & 153.2 & 158.4 & 87.6 & 84.4 & 127.0 & 129.9 \\
\hline & & $\mathrm{S}$ & 17.82 & 36.31 & 6.46 & 30.18 & 4.71 & 11.95 & 7.73 & 14.69 & 12.87 & 13.38 \\
\hline & & $\mathrm{Cv} \%$ & 12.04 & 19.94 & 5.48 & 22.82 & 3.07 & 7.54 & 8.83 & 17.39 & 10.13 & 10.30 \\
\hline & & $t_{i-f}$ & \multicolumn{2}{|c|}{1.949} & \multicolumn{2}{|c|}{$1.038 * *$} & \multicolumn{2}{|c|}{$0.928 *$} & \multicolumn{2}{|c|}{0.442} & \multicolumn{2}{|c|}{0.392} \\
\hline & & $\mathrm{p}$ & \multicolumn{2}{|c|}{$>0.05$} & \multicolumn{2}{|c|}{$>0.05$} & \multicolumn{2}{|c|}{$>0.05$} & \multicolumn{2}{|c|}{$>0.05$} & \multicolumn{2}{|c|}{$>0.05$} \\
\hline
\end{tabular}

Note: $\mathrm{t}_{\mathrm{i}-\mathrm{f}}$ - Unpaired Comparison for Means; ${ }^{*} \mathrm{p}<0.05 ;{ }^{* *} \mathrm{p}<0.01$ (F - Fisher), SPh1 - sub-phase 1 - passing over low bar; SPh2 - L.P. - sub-phase 2 body launching posture (release of bar); $\mathrm{MP}$ - FMH - multiplication of body posture - flight maximum height; $\mathrm{CP}$ - concluding body posture (landing)$\mathrm{CP} ; \mathrm{TI}$-initial testing, $\mathrm{TF}$ - final testing

Table 3. Results of correlative analysis of biomechanical indicators in the dismounts off uneven bars and results in competitions held in $2014(\mathrm{n}=8)$.

\begin{tabular}{|c|c|c|c|c|c|c|c|c|c|c|c|c|c|c|c|c|c|}
\hline \multirow{2}{*}{ No. } & \multirow{2}{*}{\multicolumn{2}{|c|}{ indicators* }} & \multicolumn{15}{|c|}{ Indicators } \\
\hline & & & 1 & 2 & 3 & 4 & 5 & 6 & 7 & 8 & 9 & 10 & 11 & 12 & 13 & 14 & 15 \\
\hline 1 & \multicolumn{2}{|c|}{ IR $\left(\mathrm{kg} \cdot \mathrm{m}^{2}\right)$} & & \begin{tabular}{|l|l|}
.677 \\
\end{tabular} & .745 & .565 & .436 & .679 & - & .899 & - & - & - & .213 & - & .296 & .094 \\
\hline 2 & \multirow{3}{*}{$\begin{array}{l}\text { RM with } \\
\text { support } \\
\text { (m) }\end{array}$} & toes & - & & .983 & .857 & .465 & .959 & .817 & .561 & - & .122 & .346 & - & - & .271 & - \\
\hline 3 & & GCG & - & - & & .828 & .572 & .965 & .848 & .618 & - & .008 & .227 & - & - & .257 & .019 \\
\hline 4 & & shoulder & - & - & - & & .194 & .706 & .517 & .557 & - & - & .527 & - & - & .154 & - \\
\hline 5 & \multirow{3}{*}{$\begin{array}{c}\text { RM w/o } \\
\text { support, } \\
\text { (m) }\end{array}$} & toes & - & - & - & - & & .521 & .522 & .622 & - & .061 & - & - & - & - & - \\
\hline 6 & & shoulder & - & - & - & - & - & & .903 & .480 & - & .098 & .218 & .011 & - & .254 & - \\
\hline 7 & & arms & \begin{tabular}{|l|}
-.432 \\
\end{tabular} & - & - & - & - & - & & .232 & - & - & .026 & - & - & .319 & .181 \\
\hline 8 & \multirow{5}{*}{$\begin{array}{c}\mathrm{KE}, \\
\text { (degrees) }\end{array}$} & SPh1 & & - & - & - & - & - & - & & - & - & - & .069 & - & .080 & - \\
\hline 9 & & SPh2.1 & \begin{tabular}{|l|}
-.432 \\
\end{tabular} & -.388 & -.349 & -.453 & -.021 & -.317 & -.074 & -.542 & & - & - & - & .579 & .479 & .626 \\
\hline 10 & & $\mathrm{SPh} 2.2$ & \begin{tabular}{|l|}
-.279 \\
\end{tabular} & - & - & -.023 & - & - & -.022 & -.071 & -.168 & & .638 & - & - & - & - \\
\hline 11 & & MP & -.131 & - & - & - & -.261 & - & - & -.037 & -.471 & - & & - & - & - & - \\
\hline 12 & & $\mathrm{CP}$ & - & -.169 & -.141 & -.439 & -.075 & - & -.049 & - & -.103 & -.182 & -.542 & & - & .286 & .206 \\
\hline 13 & \multirow{3}{*}{$\begin{array}{c}\mathrm{AA}, \\
\text { (points) }\end{array}$} & difficult & \begin{tabular}{|l|}
-.369 \\
\end{tabular} & -.557 & \begin{tabular}{|l}
-.473 \\
\end{tabular} & -.416 & -.239 & -.517 & -.201 & -.489 & - & -.743 & -.598 & -.072 & & .251 & .609 \\
\hline 14 & & execut. & - & - & - & - & -.001 & - & - & - & - & -.472 & -.500 & - & - & & .921 \\
\hline 15 & & score & - & -.003 & - & -.041 & -.104 & -.001 & - & -.132 & - & -.686 & -.651 & - & - & - & \\
\hline
\end{tabular}

Note: table 1 and 2; r- Pearson's correlation coefficient, $\mathrm{p}<0.05, \mathrm{r}=0.738 ; \mathrm{p}<0.01, \mathrm{r}=0.881$; IR - inertia of rotation, RM - radius of movement of body segments, SPh2. 1 -torso-arms angle; SPh2.2 - thigh-torso angle; KE - key elements, AA - all-around

Table 2 presents the results of biomechanical analysis indicators that characterize the kinematic structure of sports technique key elements in the dismounts off uneven bars according to the data of joints angles (using „Kinovea” program), executed in competition conditions during Romanian National Championships of Artistic Gymnastics, Bucharest 2014 and the Romanian National 
Championships of Artistic Gymnastics, Onesti 2012.

Table 3 shows the correlational links between the biomechanical indicators in the dismounts off uneven bars and the results achieved in Romanian National Championships, Bucharest 2014.

\section{Discussions}

The processing of the data existing in the years 2012, 2013 and 2014, obtained by 16 different athletes, executing 47 dismounts off uneven bars (6-TDS; 33 - PDS and 8 - TDS360 $)$ led to the determination of the values in table 2 which indicate a very good association of IR and $\mathrm{RM}^{1}$ and $\mathrm{RM}^{2}$ at toes, shoulders and arms (table no. 1).

The analysis of the kinematic structure indicators of sports technique key elements used in the dismounts off uneven bars according to the segmentary angles highlighted the mean of joints angle and the significance of the differences between tests (table 2):

- TDS $360^{\circ}(\mathrm{n}=3)$ in PM phase, during SPh1 key element, the mean of thigh - torso angle $(\bar{x} ; \mathrm{S})$ is equal to $142.7 ; 6,23^{\circ}$ - decreased by $0.4^{\circ}, \mathrm{p}>0.05$; in SPh2-LP key element, the mean of thigh - torso angle $-132.7 ; 6.74^{\circ}$ - decreased by $3^{\circ}(\mathrm{p}>0.05)$, the mean of torso-arm angle -154.7 ; $3.93^{\circ}$ - increased by $10.4^{\circ},(\mathrm{F} ; \mathrm{p}<0.01)$. In BM phase, during MP-FMH element, the mean of thigh torso angle $-86.7 ; 3.93^{\circ}$ - decreased by $18^{\circ}$, trend of improvement $-\mathrm{F} ; \mathrm{p}<0.15$. In CM phase, during $\mathrm{CP}$ element (landing), the mean of thigh - torso angle $-132.3 ; 1.45^{\circ}$ - increased by $31.6^{\circ}$ (the indicators are close to the technical requirements of FIG), $(\mathrm{F} ; \mathrm{p}<0.01)$.

PDS dismounts $(n=9)$ in PM phase, during SPh1 key element, the mean of thigh - torso angle $(\bar{x} ; \mathrm{S})$ is equal to $186.1 ; 11.33^{\circ}$ - increased by $38.1^{\circ},(\mathrm{p}<0.15)$, in SPh2-LP key element, the mean of thigh - torso angle $-139.7 ; 8.19^{\circ}$ - decreased by $21.9^{\circ}$, $(\mathrm{F} ; \mathrm{p}<0.05)$; the mean of torso-arm angle $-159.1 ; 3.59^{\circ}$ - increased by $5.9^{\circ}$, trend of improvement $(\mathrm{F} ; \mathrm{p}<0.15)$. In $\mathrm{BM}$ phase, during MP-FMH element, the mean of thigh - torso angle is equal to $75.9 ; 4.38^{\circ}$ - decreased by $11.7^{\circ}$, $\mathrm{p}>0.15$. In $\mathrm{CM}$ phase, during CP element (landing), the mean of thigh - torso angle $-135.2 ; 3.87^{\circ}-$ increased by $8.2^{\circ},(\mathrm{p}>0.05)$.

The results of the correlative analysis reveal the following matters(table 3 ): strong links between indicators $\mathrm{p}<0.01$ radius of movement (RM) of foot joint and RM of GCG and shoulder joint during rotation in handstand on apparatus; RM GCG of body and RM of shoulder joint during the phase of rotation in handstand; RM of shoulders and RM of hand joint during the phase of rotation without support; score for execution and final score. At $p<0.05$ there are correlations between the inertia of rotation (IR) and RM GCG of the body during the phase of rotation in handstand and the thigh-torso angle in SPh1; RM of foot joint and RM of shoulders during the phase of rotation in handstand and the hand joint during the phase of rotation without support; torso-arm angle during the phase of rotation without / with support and the score for exercise difficulty.

\section{Conclusion}

The comparative biomechanical analysis of the angular characteristics of sports technique key elements used in the dismounts off uneven bars executed by the gymnasts aged 12 to 15 years highlights modifications of the angular values of body posture in movement phasic structure and significant differences between tests.

The biomechanical analysis of the dismounts off uneven bars based on the achievement of the macromethods for teaching the young gymnasts aged 12 to 15 years contributed to the development of sports technique key elements and to the improvement of kinematic and dynamic characteristics of movement, which confirms the proposed hypothesis of the paper.

\section{Acknowledgement}

This case study is an advanced stage of the pedagogical experiment of the post-doctoral thesis; it is included in the research plan in the field of National University of Physical Education and Sport of Ukraine, with the subject matters: 2.32 (Technical training of qualified athlete based on competitive 
exercises technique rationalization) and in the plan of research for 2016-2017 of the Faculty of Physical Education and Sport, Ecological University of Bucharest. We express our gratitude to the Romanian Gymnastics Federation and especially to Missis Anca Grigoras Mihailescu - federal coach and to the coaches of the Olympic Team of Izvorani who helped us to conduct this research.

\section{References}

[1] V. Nicolae. Manual of sports gymnastics. Bucharest: Driada Publishing House, 1997 184-187.

[2] J. A. Leonid, G. S. Nikolai, G. C. Kak. The theory and technology of training gymnasts of your skills. Physical culture and sports. Moscow, 2004.

[3] C. Marian. Improvement of the technique of back giant and back somersault dismount off uneven bars. Piteşti: University of Piteşti, 2004.

[4] D. Tatiana, B. Mircea. Uneven bars - concept and modern methodologies. Iasi: PIM Publishing House, 2008.

[5] F. G. Emilia. Uneven bars of women's artistic gymnastics. Gymnastics. Cluj-Napoca: GMI Publishing House, vol.1, 2004.

[6] R. Lioyd. Gymnastics. Skills. Techniques. Training. Crowood sports guides. The Crowood Press Ltd, 2011.

[7] K. G. Jurij. Theory and methods of gymnastics. The textbook of vol. 1. Moscow: Soviet sports, 2014.

[8] Code of Points 2017-2020, Fédération Internationale de Gymnastique, Women's Artistic Gymnastics, Part III, Apparatus, Section 11 - Uneven Bars; Part IV Tables of elements, 43-45 (2017) 103.

[9] C. Marian, S. Ion, B. Mircea. Biomechanics of back giant on uneven bars. Pitesti: Publishing House of Pitești University, 2004.

[10] J. H. Michael, M. R. Yeadon. The Margin for Error When Releasing the Asymmetric Bars for Dismounts, J. Appl. Biomech. (21) (2005) 223-235.

[11] J. H. Michael, M. R. Yeadon. Optimization of Backward Giant Circle Technique on the Asymmetric Bars, J. Appl. Biomech. (23) (2007) 300-308.

[12] P. Vladimir, G. Vasilica, C. T. Olivia, V. U. Marius. Biomechanical characteristics of transfer in the rotation movements on uneven bars, Appl. Mech. Mater. 656 (2014) 650-660.

[13] P. Vladimir, C. T. Olivia, M. Costin, M. Carmen. Biomechanical characteristics of back double salto dismount off uneven bars, J. Phys. Edu. Sport. 2 (2014) 248-253.

[14] P. Vladimir. Biomechanical Analysis of Sports Technique Key Elements in Back Double Somersault Dismount off Uneven Bars - Junior Gymnasts 12 to 14 Years Old, Proc. Soc. Behav. Sci. 117 (2014) 203-209.

[15] P. Vladimir, G. Vasilica, T. Olivia. Biomechanical characteristics of key elements of Gienger salto technique on uneven bars, Proc. Soc. Behav. Sci. 191 (2015) 372-377.

[16] P. Vladimir, T. Olivia, T. Vasile. Biomechanical characteristics of key elements of Jaeger salto technique on uneven bars. Proceedings Of The 6th Annual International Conference: Physical Education Sport and Health, University of Pitesti, (17/1) (2013) 257-261.

[17] P. Vladimir. Bases of Macromethods for Sports Exercises Learning (material from women's artistic gymnastics). Monograph, Kiev: Center Education Literature, 2015.

[18] B. Victor. Regulation of body posture athlete. Monography. Kiev: Olympic Literature, 2013 
118-190. 